\title{
Evidence to Clinch the Theory of Extraterrestrial Life
}

\section{Chandra Wickramasinghe $\mathbf{N}^{1,2,3}$}

${ }^{1}$ Buckingham Centre for Astrobiology (BCAB), Buckingham University, UK ${ }^{2}$ Institute for the Study of Panspermia and Astroeconomics, Gifu, Japan

${ }^{3}$ University of Peradeniya, Peradeniya, Sri Lanka

New data may serve to bring about the long overdue paradigm shift from theories of Earth-centred life to life being a truly cosmic phenomenon. The theory that bacteria and viruses similar to those on Earth exist in comets, other planets and generally throughout the galaxy was developed as a serious scientific discipline from the early 1980's [1-4]. Throughout the past three decades this idea has often been the subject of criticism, denial or even ridicule. Even though many discoveries in astronomy, geology and biology continued to provide supportive evidence for the theory of cosmic life, the rival theory of Earth-centered biology has remained deeply rooted in scientific culture. However, several recent developments are beginning to strain the credibility of the standard point of view.

The great abundance of highly complex organic molecules in interstellar clouds [5], the plentiful existence of habitable planets in the galaxy numbering over 100 billion and separated one from another just by a few light years [6], the extreme space-survival properties of bacteria and viruses -make it exceedingly difficult to avoid the conclusion that the entire galaxy is a single connected biosphere. The patterns of evolution of life found on the Earth are therefore likely to be repeated on countless planets, with each individual planetary environment selecting its genetic inheritance from a vast cosmic reservoir of genes. These ideas have been elaborated upon in several papers $[7,8]$.

In this brief commentary I wish to draw attention to three new developments that make the switch from Earth-centred to cosmiccentred life imperative. Firstly, discoveries of living bacteria and biomorphs in the stratosphere which could not have been plausibly lofted from the Earth's surface continue to point to their origin from cometary sources $[9,10]$. More work is needed of course to decisively clinch this matter, but the signs are already clear that our planet is by no means sealed from external biological contaminants. Secondly, new Rosetta data for Comet 67P/CG makes it increasingly difficult to avoid the conclusion that microbial life in the comet is indeed plentiful and could account for several of its salient features $[11,12]$.

As far back as 1986 Hoyle and the present writer predicted a low albedo of comets based on the hypothesis of a biological comet [13]. When aqueous regions near the comet's surface containing a suspension of microbial particles and sub-micron mineral dust evaporate in a low density cometary environment, loosely compacted factal structures are likely to build up into a surface layer. It is such a layer that can elegantly explain the low optical albedo $<0.06$ found for comet Halley as well as comet $67 \mathrm{P} / \mathrm{C}-\mathrm{G}$.

Observations of comet $67 \mathrm{P} / \mathrm{C}-\mathrm{G}$ have also borne out the prediction of a surface laden with complex organics in the form of a broad 3.3 micrometer absorption feature [13] in the spectrum of reflected light (Figure 1). The existence of organic/mineral dust complexes in particle collections that are fractal on scales of 10 micrometres to tens of nanometers is also indicated Rosetta's COSIMA and MIDAS measurements $[14,15]$ (Figure 2).

In conclusion it is worth noting here that the long-disputed discovery by Levin and Straat [16] of evidence of extant microbial life on Mars (in the Labelled Release experiment on the 1976 Viking probe) appears to have been finally vindicated, both by the discovery of organic molecules on the surface, and more dramatically by the recent discovery of time-variable spikes in methane observed by the Curiosity

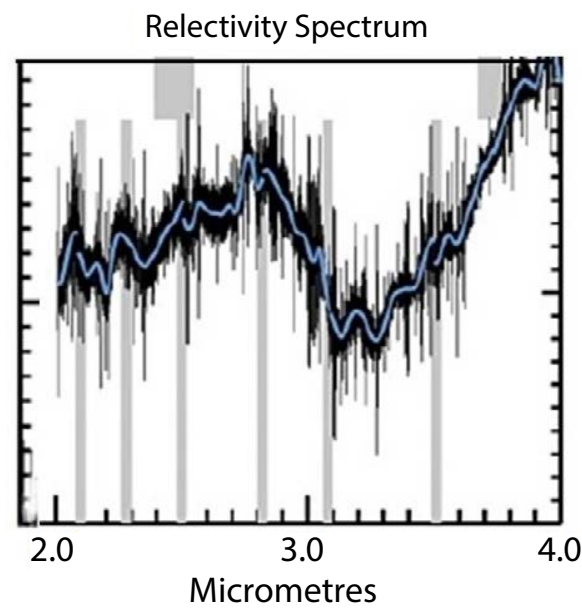

Figure 1: Reflectance spectrum of the surface of comet $67 \mathrm{P} / \mathrm{C}-\mathrm{G}$ showing broad peak at 3.3 micrometres.

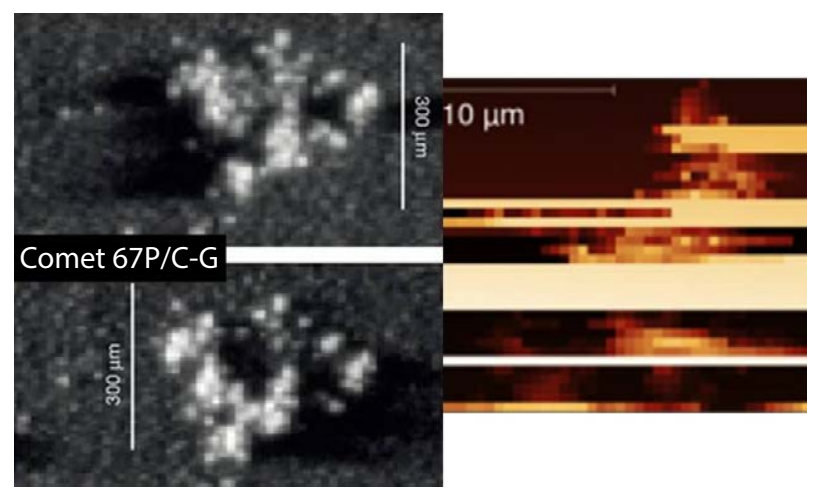

Figure 2: Left: 300 micron sized disintegrating dust clump studied by Rosetta's COSIMA; Right: Atomic force microscope scan of the first MIDAS particle reported by Bentley.

*Corresponding author: Wickramasinghe NC, Buckingham Centre for Astrobiology (BCAB), Buckingham University, UK, Tel: +44-777-838-9243; E-mail: ncwick@gmail.com

Received February 11, 2015; Accepted February 16, 2015; Published February 20, 2015

Citation: Chandra Wickramasinghe N (2015) Evidence to Clinch the Theory of Extraterrestrial Life. Astrobiol Outreach 3: e107. doi:10.4172/2332-2519.1000e107

Copyright: (c) 2015 Chandra Wickramasinghe N. This is an open-access article distributed under the terms of the Creative Commons Attribution License, which permits unrestricted use, distribution, and reproduction in any medium, provided the original author and source are credited. 
Citation: Chandra Wickramasinghe N (2015) Evidence to Clinch the Theory of Extraterrestrial Life. Astrobiol Outreach 3: e107. doi:10.4172/23322519.1000e107

Page 2 of 2

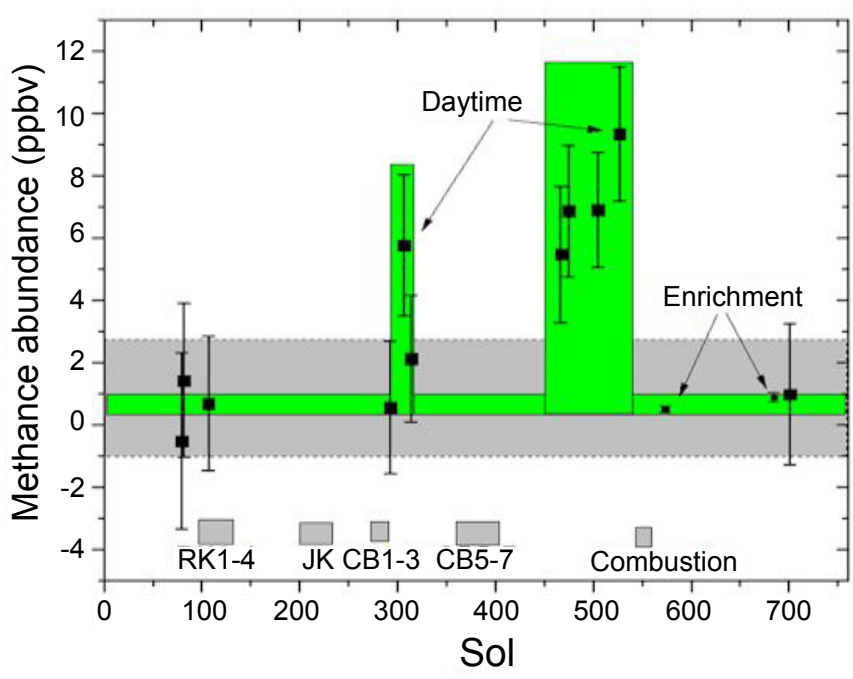

Figure 3: Methane abundance vs. Martian sol.

Rover [17] as displayed in Figure 3. Ongoing subsurface microbiology yielding methane as a metabolite is the simplest explanation of this data.

At long last the tide appears to have turned in favour of the idea if extraterrestial biology. However, if one still insists that life started in situ on the Earth and that comets could at best serve as deliverers of necessary organics and water, it may still be possible to accommodate the new facts provided ad hoc assumptions are made. The situation would be similar to the introduction of epicycles in the Ptolemaic theory that delayed the acceptance of a heliocentric planetary system. How many such epicycles would be needed for the second Copernican Revolution remains to be seen.

\section{References}

1. Hoyle F, Wickramasinghe NC (1981) Comets and the Origin of Life. World Scientific Publishing Co Pte Ltd.
2. Hoyle F, Wickramasinghe NC (1981) Evolution from Space. Dent JM and Sons London. Touchstone; Reprint edition.

3. Hoyle F, Wickramasinghe NC (1981) Living Comets. Cardiff: Univ. College, Cardiff Press.

4. Wickramasinghe NC (2015) The search for our cosmic ancestry. World Scientific Publishing.

5. Wickramasinghe NC (2010) The astrobiological case for our cosmic ancestry International Journal of Astrobiology 9: 119.

6. Wickramasinghe NC, Smith WE (2015) Convergence to Panspermia. Hypothesis 12: e9.

7. Wickramasinghe NC (2012) DNA sequencing and predictions of the cosmic theory of life. Astrophys Space Sci 343: 1-5.

8. Tokoro G, Wickramasinghe NC (2014) The socio-economic control of a scientific paradigm: life as a cosmic phenomenon. Journal of cosmology 2: 115 .

9. Wickramasinghe NC, Wainwright M, Narlikar JV, Rajaratnnm P, Harris MJ, et al. (2013) Progress towards the vindication of panspermia. Astrophysics and Space Science 283: 403

10. Wainwright M, Wickramasinghe NC (2015) The Transition from Earth-centred Biology to Cosmic Life. Journal of Astrobiology and Outreach, in press

11. Wickramasinghe NC, Wainwright M (2015) Rosetta images of Comet 67P/ Churyumov-Gerasimenko 2. Prospects for cometary biology. Journal of Astrobiology and Outreach, in press.

12. Wickramasinghe NC, Wallis $M$ (2015) Rosetta images of Comet 67P/ Churyumov-Gerasimenko 1: Near-surface icy terrain similar to comet Tempel-1. Journal of Astrobiology and Outreach, in press.

13. Capaccione F, Coradini A, Filacchione G (2015) The organic-rich surface of comet $67 \mathrm{P} /$ Churyomov-Gerasimenko as seen by VIRTIS/Rosetta. Science, 347: aaa0628.

14. Schulz R, Hilchenbach M, Langevin Y, Kissel J, Silen J, et al. (2015) Comet $67 \mathrm{P} / \mathrm{Churyumov}-\mathrm{Gerasimenko}$ sheds dust coat accumulated over the past four years. Nature 518: 216-218

15. Bentley (2014) Midas and its first dust grain. European Space Agency.

16. Levin GV, Straat PA (1976) Martian Life Detection with Amino Acid Enantiomers. Science 194 : 1322-1329.

17. Webster CR, Mahaffy PR, Atreya SK, Flesch GJ, Mischna MA, et al. (2015) Mars methane detection and variability at Gale crater. Science 347: 415-417. 